\title{
Article
}

\section{Feasibility of Solar Grid-Based Industrial Virtual Power Plant for Optimal Energy Scheduling: A Case of Indian Power Sector}

\author{
Harpreet Sharma $^{1}$, Sachin Mishra ${ }^{2}$, Javed Dhillon ${ }^{2}{ }^{(\mathbb{D}}$, Naveen Kumar Sharma ${ }^{3}$, Mohit Bajaj ${ }^{4}{ }^{-}$, Rizwan Tariq ${ }^{5}$, \\ Ateeq Ur Rehman ${ }^{6, *(\mathbb{D}}$, Muhammad Shafiq $7, * \mathbb{C}$ and Habib Hamam $8,9,10 \mathbb{C}$
}

1 Punjab State Power Corporation Limited, Punjab 144001, India; harpreetsharma1981@gmail.com

2 School of Electronics and Electrical Engineering, Lovely Professional University, Phagwara 144411, India; rite2sm@gmail.com (S.M.); javed364@gmail.com (J.D.)

3 Department of Electrical Engineering, I. K. Gujral Punjab Technical University, Jalandhar 144603, India; naveen31.sharma@gmail.com

4 Department of Electrical and Electronics Engineering, National Institute of Technology, Delhi 110040, India; mohitbajaj@nitdelhi.ac.in

5 Department of Electrical Engineering, Universiti Kuala Lumpur-BMI (UniKL-BMI), Gombak 53100, Malaysia; Engr.rizwan101@gmail.com

6 Department of Electrical Engineering, Government College University, Lahore 54000, Pakistan

7 Department of Information and Communication Engineering, Yeungnam University, Gyeongsan 38541, Korea

8 Faculty of Engineering, Moncton University, Moncton, NB E1A3E9, Canada; Habib.Hamam@umoncton.ca

9 Spectrum of Knowledge Production and Skills Development, Sfax 3027, Tunisia

10 Department of Electrical and Electronic Engineering Science, School of Electrical Engineering, University of Johannesburg, Johannesburg 2006, South Africa

* Correspondence: ateqrehman@gmail.com (A.U.R.); shafiq@ynu.ac.kr (M.S.)

check for

updates

Citation: Sharma, H.; Mishra, S.; Dhillon, J.; Sharma, N.K.; Bajaj, M.; Tariq, R.; Rehman, A.U.; Shafiq, M.; Hamam, H. Feasibility of Solar Grid-Based Industrial Virtual Power Plant for Optimal Energy Scheduling: A Case of Indian Power Sector Energies 2022, 15, 752. https:// doi.org/10.3390/en15030752

Academic Editor: Bilal Asad

Received: 24 November 2021

Accepted: 15 January 2022

Published: 20 January 2022

Publisher's Note: MDPI stays neutral with regard to jurisdictional claims in published maps and institutional affiliations.

Copyright: (c) 2022 by the authors. Licensee MDPI, Basel, Switzerland. This article is an open access article distributed under the terms and conditions of the Creative Commons Attribution (CC BY) license (https:// creativecommons.org/licenses/by/ $4.0 /)$.

\begin{abstract}
The increased popularity of small-scale DER has replaced the well-established concept of conventional generating plants around the world. In the present energy scenario, a significant share of energy production now comes from the grid integrated DERs installed at various consumer premises. These DERs are being renewable-based generates only intermittent power, which in turn makes the scheduling of electrical dispatch a tough task. The Virtual Power Plant (VPP) is a potential solution to this challenge, which coordinates and aggregates the DERs generation into a single controllable profile. In this paper, a modified PSO-based multi-objective optimization is proposed for the VPP scheduling in distribution network applications such as energy cost minimization, peak shaving, and reliability improvement. For feasibility analysis of the VPP, a case study of state power utility is taken, which includes a 90 bus industrial feeder with grid integrated PVs as DER. The optimized results are computed in both grid-connected and autonomous mode reveal that the operating cost, peak demand, and EENS are declined by $31.70 \%, 23.59 \%$, and $62.30 \%$ respectively. The overall results obtained are compared by the results obtained from other well-established optimization techniques and it is found that the proposed technique is comparatively more cost-effective than others.
\end{abstract}

Keywords: virtual power plant; solar $P V$; net-metering; distributed energy resources; battery storage

\section{Introduction}

\subsection{VPP Concept}

The modernization of the present grid infrastructure through the implementation of smart grid technologies is now one of the top priorities of various nations of the world. In the last decade, the biggest change that the current distribution network had witnessed is the introduction of the Virtual Power Plant (VPP). The VPP is the big forward step taken in the path of the sustainable and robust energy future through its efficient and autonomous operation [1,2]. The core components of the VPP include Grid interconnected Distributed Energy Resource (DER), Energy Storage System (ESS), flexible loads, and communication technologies [3]. In VPP, the DERs of small rating and having a low starting period such 
as solar $P V$, wind, and gas turbines are utilized. Nowadays these DERs are installed at industrial premises and their generation is aggregated, in such a way that their small rating gets visible to the grid operator as a central power generator. Most of the DERs are utilized in the VPP are renewable ones so, to tackle the intermittent generation issues, the ESS could be an effective way to suppress the variation in their generation and provide dispatchable generation [4]. Another distinctive feature of the VPP is the load following, in which certain conditions, the flexible load can be used to follow the intermittent renewable generation through the Demand Side Management (DSM) programs [5-11]. The continuous interaction of the different components of the VPP and the grid is only possible through Information technologies, which provide real-time data to the grid operator to decide while the dispatching and scheduling of energy. In this paper, a case study of state utility is taken to analyze the implications of the VPP implementation. The technical and commercial aspects for both utility and consumer are considered while optimal energy scheduling. The PSO-based multi-objective model is designed for the objectives such as reliability enhancement, reduction of peak load, and total energy cost.

\subsection{Literature Review}

In [12] the VPP model is proposed, which offers the coordinated operation of electrical and gas networks. This research evaluated the role of DR models such as coupon-based and interruptible load-based models are evaluated on 118 bus IEEE feeder for cost minimization using bi-level optimization, however, the use of DER and energy storage is not included. The Industrial VPP model is introduced in [13] for the management of industrial loads and generation using stochastic Mixed-Integer Non-Linear Programming (MINLP). This study includes wind generators and DR programs, however, the utility impact is not taken into account, moreover, the storage devices are not used during dispatch. In research [14] aggregate generation and demand response of the prosumers is scheduled optimally for the day-ahead energy market using a two-stage Stackelberg model without giving stress on the technical aspects of the utility including energy storage. In [15] the mixed optimization, which is the combination of interval and deterministic approach is utilized for solving the VPP dispatch problem without taking the reliability aspect of the utility. The combined dispatch of energy and reserve is proposed in [16] with a probabilistic modified decisionmaking model with the inclusion of DER, storage, EV, and demand response, however, there is no consideration is given to the influence of VPP on the reliability of the utility network. In [17] the VPP based on a multi-objective model is introduced to maximize revenue, minimize risk, and minimize carbon emission using robust optimization theory. This study doesn't take utility benefits such as peak load reduction and reliability enhancement into account. The techno-economic aspects of VPP for a case study of university campus using the co-optimized model is introduced in [18] with different DERs, DR, and energy storage devices without studying the implications of the utility. The MILP optimization for techno-economic optimal dispatch VPP model is proposed in [19] for the integration of large and small scale DERs with the objective of energy cost minimization, however, the application of DR and energy storage are not included in this study. The study [20] introduces a multi-objective VPP model for maximizing day-ahead profits and minimizing carbon emissions using two stages stochastic without the inclusion of DR. The technoeconomic assessment of VPP with DR for day-ahead scheduling is given in [21] using a modified differential evolution algorithm, however, impact on utility is not evaluated in this research. In [22] the combined electrical and economical behavior of VPP is analyzed in a real-time case study without utilizing DR and utility technical constraints.

\subsection{Literature Gap and Research Contributions}

Most of the reported literature is concerned with the VPP scheduling for cost minimization from the consumer point of view. The positive influence of the VPP on the reliability enhancement and peak shaving with respect to power utility has not been taken into account by any reported study. Moreover, to our best knowledge, the autonomous 
operation of VPP during an outage is still not studied. In addition to that, the optimization of the multi-objective model of VPP with the Particle Swarm Optimization (PSO) algorithm is still missing.

The prime objective of the paper is to fill the research gap and to propose the novel application of the VPP in enhancing the distribution network reliability with its autonomous operation. In this paper, a multi-objective VPP model is designed with the objective of cost minimization, peak load reduction, and reliability enhancement while considering both VPP grid-connected and autonomous operation. The modified PSO algorithm is utilized in this research for the optimization of the VPP dispatch strategy while considering benefits and constraints from both the utility and consumer point of view. A real-time case study of 90 bus Industrial feeders is selected for the evaluation of the proposed VPP model implementation. The paper is organized as follows: In Section 2 a case study of a utility network is analyzed including its technical and commercial parameters. Section 3 explains the mathematical modeling of various components of the VPP. Section 4 describes the objective function and optimization algorithm for the dispatch strategy. In Section 5 results of different cases of VPP are discussed and techno-economic analysis of the VPP is performed. In Section 6 the detailed comparison is given with other optimization algorithms. Section 7 concludes the major results and future scope of the research have been discussed.

\section{Case Study}

The Punjab State Power Corporation Limited (PSPCL), a government-owned power utility, has been studied for feasibility analysis of the solar grid-based VPP [23]. The PSPCL has a monopoly in the power sector of the state of Punjab (India), however, due to full government control, it puts continuous efforts into achieving a sustainable energy future. The company introduces numerous schemes to motivate the consumers to install the gridconnected small-scale DERs such as roof-top $P V$ on the premises. The benefits of installing the multiple DERs at different locations are not limited to the consumer, but also for the utility in reliability improvement and peak load shaving. There are limited studies of the VPP application is available for the industrial feeder, so in this case study, an industrial feeder has been taken to analyze the implications of the VPP in techno-economic terms. The VPP is based on the 90-bus feeder model, which is designed in ETAP (Figure A1), in which the feeder length is divided into different sections depending upon the location of reclosers (in Appendix B). A typical section of the feeder includes the overhead ACSR conductor, a distribution transformer, a lumped load, and aggregated solar $P V$ with a controllable switch. The recloser is also installed at various points of the main length of the feeder for the isolation and autonomous operation of the remaining feeder. In grid-connected mode, the combined solar generation is dispatched with the motive of peak load reduction and reduced utility imports. However, to enhance the reliability, the VPP can be operated in autonomous mode, which fed the load of the particular section of the feeder, while isolating the faulty section of the line with reclosers.

The real-time data of $P V$ generation and demand has been taken from the smart meter installed at a distribution transformer and consumer premises. The study is classified into two operating modes (Grid connected and Autonomous) and further these modes are categorized into three different cases, which are as follows:

1. Base case with DER.

2. Base case with DER and DR.

3. Base case with DER, DR, and Storage.

\section{VPP Modelling}

The individual mathematical modeling of the various components of the VPP is as follows: 


\subsection{Solar PV}

It is one of the widely popular DER as most of the regions around the world receive sufficient solar radiation. The $P V$ technology used in the study is cadmium telluride with a lifetime of 20 years. The solar panel is assumed to install at every industrial consumer and its maximum aggregated capacity is capped to $1916 \mathrm{~kW}$ in the feeder. The output of the solar $P V$ is given as:

$$
P_{V e o}=A \times \eta \times N \times S_{t} \forall t \in T \quad(k W)
$$

$\eta=$ Efficiency of a solar panel (14.9\%)

$S_{t}=$ Solar irradiation $\left(\mathrm{W} / \mathrm{m}^{2}\right)$

$t=$ Time step $(\mathrm{h})$

$N=$ Number of solar panels connected (no)

$A=$ Area occupied by solar panels $\left(\mathrm{m}^{2}\right)$

$T=$ Total time period (h)

$P_{V e o}=$ Estimated output of solar $P V, P V s o=$ Scheduled output of solar $P V$, Lifetime of $P V=25$ years

$P V$ Inverter size $=1.05^{*}$ solar capacity

It is assumed that the $P V$ panels are fully reliable and integrated with an inverter of the same rating. The maximum grid integrated capacity of $P V$ is capped to $20 \%$ of transformer capacity due to safety constraints. The average daily $P V$ generation $(\mathrm{kW})$ for November month is shown in Figure 1 below.

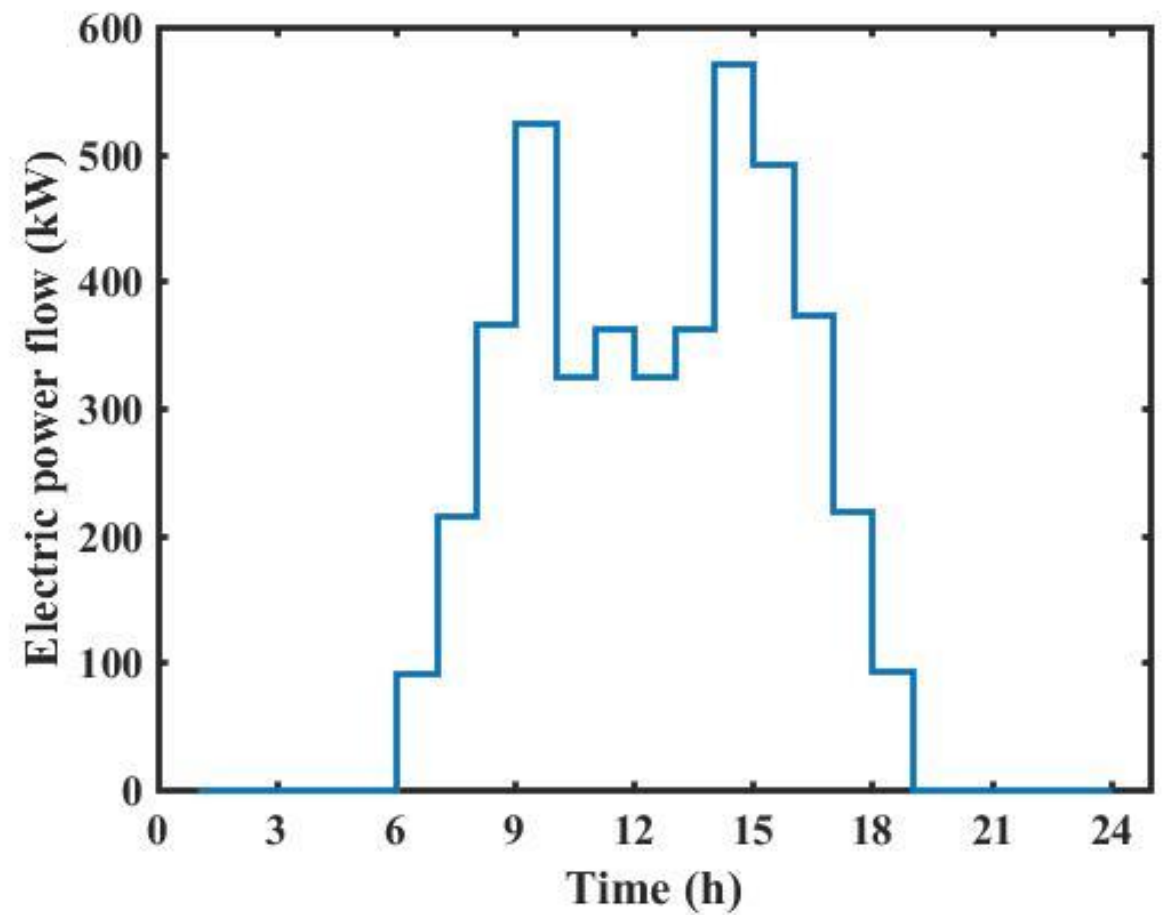

Figure 1. $P V$ generation $(\mathrm{kW})$.

The solar radiations are varying with different seasons and cloud movements, which have a direct influence on the $P V$ output. The average solar radiations received by the study area are abundant in the comparison of the world average as its location is proximate to the equator. The average solar radiation and clearness index data is illustrated in Figure 2 where the radiations are maximum in the month of September; however, the clearness index also influences the $P V$ generation during that period. 


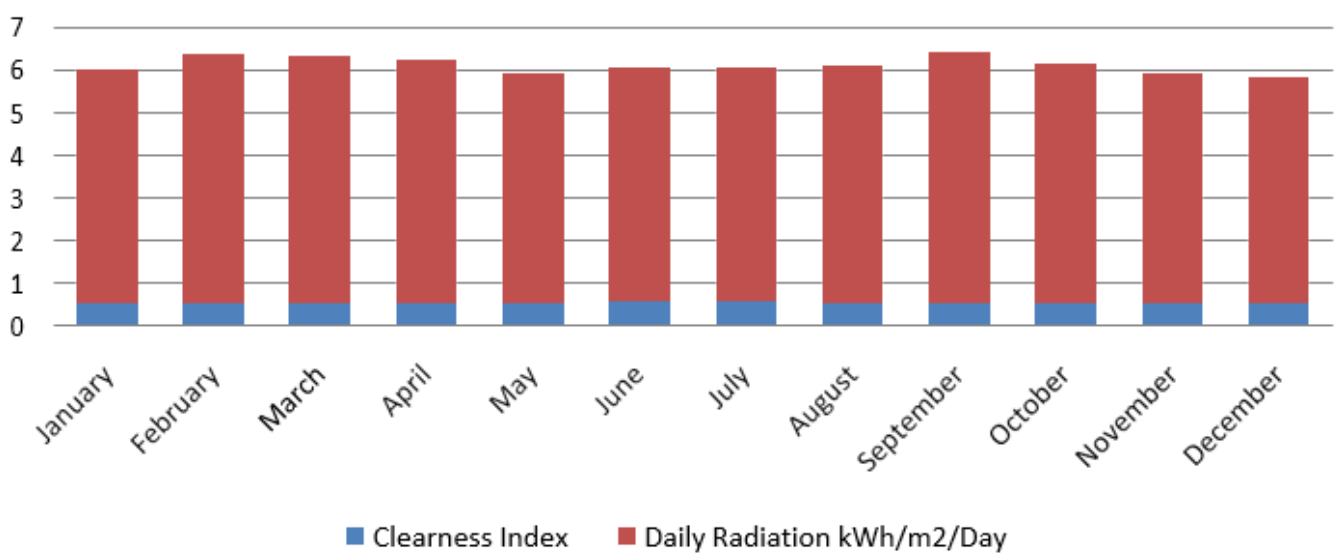

Figure 2. Average solar radiation and clearness index.

\subsection{Battery}

The renewable-based DERs usually have highly fluctuated and time-dependent generation, which needs storage technology like batteries to smooth out its output variations. It stores the excess energy in a low demand period and releases this stored energy during high demand or low generation period. The operational cost of the battery is given as [24]:

$$
P_{t}^{b a t}=m_{t}^{b a t} \times E_{t}^{b a t}+d_{t}^{b a t} \times E_{t}^{b a t}+E_{t}^{b a t} \times p o l_{t}^{b a t} \quad \forall t \in T
$$

$P_{t}^{b a t}=$ Operational price of battery in dispatch (\$)

$m_{t}^{\text {bat }}=$ maintenance coefficient of battery

$E_{t}^{b a t}=$ Discharging or recharging of the battery $(\mathrm{AH})$

$d_{t}^{b a t}=$ Depreciation coefficient of the battery

pol $l_{t}^{\text {bat }}=$ Pollution coefficient of the treatment cost

$t=$ Timestep $(\mathrm{h})$

$T=$ Total time period (h)

The battery capacity is taken as $9500 \mathrm{kWh}$ and with a lifetime of 5 years. The round trip efficiency is $90 \%$. The maximum charge and discharge rate is $30 \%$ of the total battery capacity.

\subsection{Loads}

The load is provided by a SCADA-controlled $66 / 11 \mathrm{kV}$ step-down substation situated inside the division's boundaries. The $11 \mathrm{kV}$ Industrial feeder on which the DERs are mounted is chosen for load evaluation in this study. The load profile of the feeder is combined into a single operational profile and assessed for various scenarios. The modeling of the load is as follows:

$$
\text { Load }_{t}=\text { Flex }_{t}+\text { Intrr }_{t}+\text { Emg }_{t} \forall t \in T
$$

Load $_{t}=$ Total demand on the feeder

Flex $x_{t}=$ Schedulable demand

Intrr $_{t}=$ Non-Schedulable demand

$E m g_{t}=$ Emergency demand $t=$ Timestep

The flexible load can be shifted from peak time to off-peak period, whereas the nonflexible demand cannot be scheduled to any other time of day. The emergency demand, which includes high priority loads, is needed to supply at any cost even during a grid outage. The loading and reliability parameters of the industrial feeder are tabulated in Table 1 below. 
Table 1. PSPCL Load and Reliability data.

\begin{tabular}{lc}
\hline \multicolumn{2}{l}{ Industrial Feeder } \\
\hline & Loading Parameters \\
\hline Average demand & $1033 \mathrm{~kW}$ \\
\hline Peak demand & $4288 \mathrm{~kW}$ \\
\hline Annual energy demand & $9,718,850 \mathrm{kWh}$ \\
\hline Peak Month & November \\
\hline Total consumers & 257 \\
\hline Length & $2174 \mathrm{~m}$ \\
\hline Current capacity & $254 \mathrm{Amp}$ \\
\hline kVA capacity on 11 kV & $4839 \mathrm{kVA}$ \\
\hline Maximum demand & $290 \mathrm{Amp} / 5518 \mathrm{kVA}$ \\
\hline & \\
\hline No. of Transformers & 47 \\
\hline Transformer Failure rate/year & 0.15 \\
\hline Transformer Mean time to repair & $0.5 \mathrm{~h}$ \\
\hline No. of sectional lines & 41 \\
\hline Sectional Lines Failure rate/year & 0.5 \\
\hline Sectional Lines Mean time to repair & $1.5 \mathrm{~h}$ \\
\hline No. of Substations & 1 \\
\hline Substation Failure rate/year & 0.6 \\
\hline Substation Meantime to repair & $4 \mathrm{~h}$ \\
\hline
\end{tabular}

\subsection{Main Grid}

The PSPCL $11 \mathrm{kV}$ distribution network with grid integrated DERs allows both energy import and energy export at different points of the feeder. The net-metering policy makes effective $P V$ utilization possible both with and without the battery storage through the application of a smart meter at prosumer premises. The net metering policy and the Time of Day (ToD)tariff are utilized for flattening the load profile and the same is used for this study 2018-2019 [25]. The major goal of this tariff is to minimize peak-hour demand by promoting users to move their load from on-peak to off-peak hours, allowing the utility to postpone expenditure in generating and distribution capacity. The main features of this tariff are shown in Table 2 below.

Table 2. PSPCL ToD tariff.

\begin{tabular}{clc}
\hline Period & \multicolumn{1}{c}{ Time } & Cost/kWh \\
\hline \multirow{2}{*}{ 1 April 2018 to 31 May 2018 } & 06:00 a.m. To 06:00 p.m. & \multirow{2}{*}{$\$ 0.09$} \\
\cline { 2 - 2 } & \multicolumn{1}{c}{ 06:00 p.m. To 10:00 p.m. } & \\
\cline { 2 - 3 } & 10:00 p.m. To 06:00 a.m. & $\$ 0.07$ \\
\hline \multirow{2}{*}{ 1 June 2018 to 30 September 2018 } & 06:00 a.m. To 06:00 p.m. & $\$ 0.09$ \\
\cline { 2 - 3 } & 06:00 p.m. To 10:00 p.m. & $\$ 0.12$ \\
\hline \multirow{2}{*}{ 1 October 2018 to 31 March 2019 } & 10:00 p.m. To 06:00 a.m. & $\$ 0.09$ \\
\cline { 2 - 3 } & 06:00 a.m. To 06:00 p.m. & $\$ 0.09$ \\
\hline
\end{tabular}


The equations showing the import and export prices of electricity of the PSPCL:

$$
\begin{gathered}
C_{I m p, t}^{V P P}=T o D\left(C_{I m p, t}^{P s p c l}\right) \forall t \in T \text { Purchasing cost of energy from the PSPCL } \\
C_{E x p, t}^{V P P}=T o D\left(C_{E x p, t}^{P s p l}\right) \forall t \in T \text { Selling cos t of energy to the PSPCL }
\end{gathered}
$$

The rates for energy import and export are the same, but there is an annual cap on the maximum generation and energy export. The variation in the cost of energy at various time intervals is shown in Figure 3.

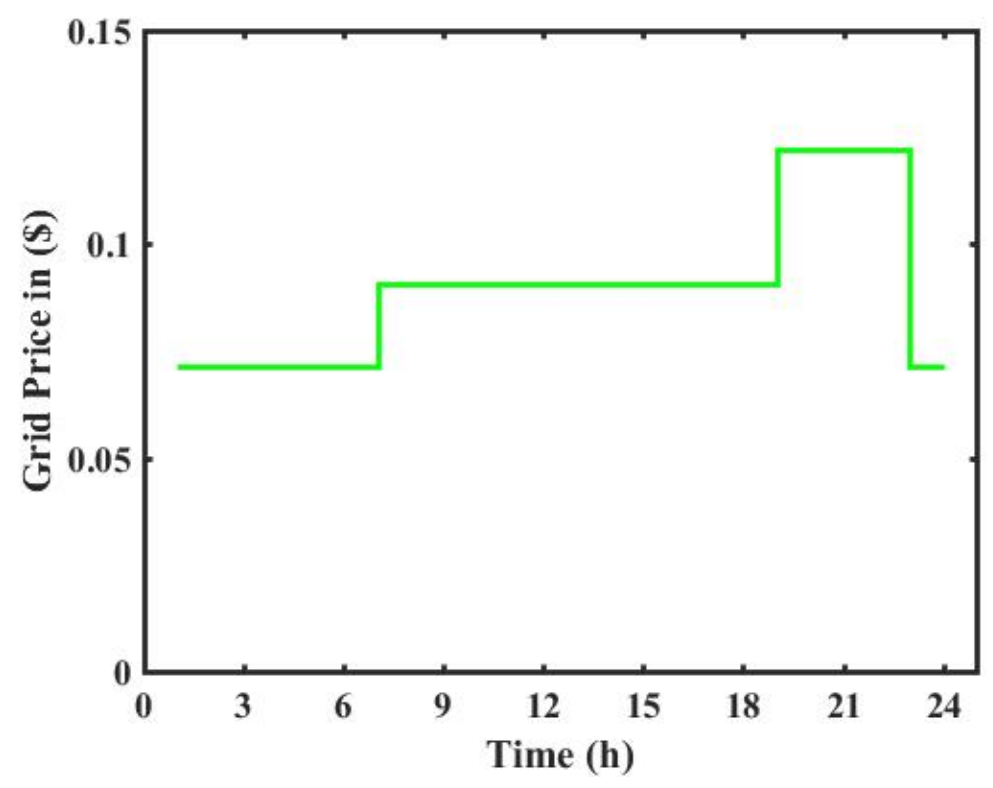

Figure 3. Grid price variation.

The price variation is based on the different seasons and government policies on consumption and generation patterns.

\section{Objective Function and Constraints}

The objective function of the designed model has three main motives: meet the electrical demand with the least cost, reduce the maximum demand, and enhance the system reliability. In this designed model, the VPP dispatch the various resources according to the minimal cost and its availability.

The objective function of the study is:

$$
C_{t}^{V P P}=C_{t}^{P V}+C_{t}^{B a t}+C_{t}^{G r i d}+C_{t}^{E E N S}
$$

Equation (6) above shows the total cost of the VPP which is needed to minimize and it includes the cost of dispatch with $P V$, batteries, grid, and cost incurred due to Expected Energy Not Supplied (EENS). The factors, which affect the battery and $P V$ output:

Dis $R_{t}^{\text {bat }}=$ Discharging rate of the battery

$C h r R_{t}^{\text {bat }}=$ Charging rate of the battery

TotCap bat $=$ Total capacity of the battery

$C a p_{t}^{b a t}=$ Initial capacity of the battery

Max $S=$ Maximum rating of solar $P V$

$N S=$ Number of units of solar $P V$ installed

MaxH = Maximum annual operation hours for $P V$ technology 
The constraints for this objective function are as follows:

$$
\begin{aligned}
& \operatorname{Load}_{t}=\sum P V_{s o}+U_{\text {Loadt }}^{\text {Imp }}+\sum \operatorname{TotCap}_{t}^{\text {bat }} \quad k W \\
& \operatorname{Dis}_{t}^{b a t}=\left(\frac{\operatorname{Tot}^{b a p} p_{t}^{b a t}}{12}\right) \times\left(\left(\frac{\operatorname{Cap}_{t}^{b a t}}{\operatorname{Tot} C a p_{t}^{b a t}}\right)^{0.5}\right) \\
& \operatorname{Cap}_{t}^{b a t}=\left(\operatorname{Dis}_{t}^{b a t}-\left(\operatorname{Tot} C a p_{t}^{b a t} / 10\right)\right) \\
& \sum\left(\sum P V_{\text {so }}+U_{\text {Loadt }}^{\text {Exp }}\right) \leq N S \times M a x S \times M a x H \\
& \text { EENS }=\text { Load }_{t}-\text { Flex }_{t}-\text { Intrr }_{t}-P V_{\text {so }}-\text { TotCap }_{t}^{\text {bat }}
\end{aligned}
$$

Equation (7) shows balancing between load, $P V$ generation, and utility imports. To minimize the EENS, the portion of the total load is either curtailed or shifted depending upon its priority. The remaining high priority load is supplied through the $P V$ generation and battery storage as per the availability.

Equation (8) shows the discharge rate of the battery, which depends on the initial capacity and total capacity of the battery.

Equation (9) gives the rate of charging, which is based on the discharging rate and total capacity of the battery.

Equation (10) shows the maximum $P V$ generation constraint which depends on the number of $P V$ panels and their operating duration.

Equation (11) computes EENS during the fault period after utilizing the output from $P V$, battery, and DR. $\times 9$.

Assumptions:

- $\quad P V$ Capacity $\leq 20 \%$ of Transformer Capacity (to prevent reverse power flow during low demand)

- $\quad P V$ Capacity $\leq 80 \%$ of Connected Load

- Battery Maximum Discharge Capacity $\leq 20 \%$ of total storage capacity (to prevent reduction of battery life)

- The initial capacity of the battery $=500 \mathrm{kWh}$.

\section{PSO and Dispatch Strategy}

The PSO well-known optimization technique which is utilized in numerous optimization problems, which is initially introduced by Kennedy in 1995. It was the simplest version of PSO which is later modified by shi by adding a new parameter inertia weight. PSO itself is the simplest form of optimization and it is easy to implement. The computational cost of PSO is lower and has only a few initial parameters than other heuristic optimization techniques. Furthermore, PSO is less dependent on initial values than other techniques and generate high-quality solution [26]. Undoubtedly, the effectiveness of this optimization is un-matching, however with inclusions of different variables and constraints, the resultant convergence time is too long $[27,28]$. Although, the modification of the Kennedy PSO version is done by limiting the search area by concerning VPP constraints, which keeps its simplicity and results in less convergence time as demonstrated in Appendix A. The three major global variables of the PSO algorithm are:

(1) Gbest (global best solution of each particle)

(2) Target objective

(3) Stopping criteria

Further, each particle has three types of data:

(1) Pbest (particle valid solution)

(2) Particle velocity

(3) Particle best known local solution 
To limit the search space, the information is taken from an experienced member's memories of the swarm and by eliminating the search in the worst places. The flowchart of the PSO algorithm is illustrated in Figure 4.

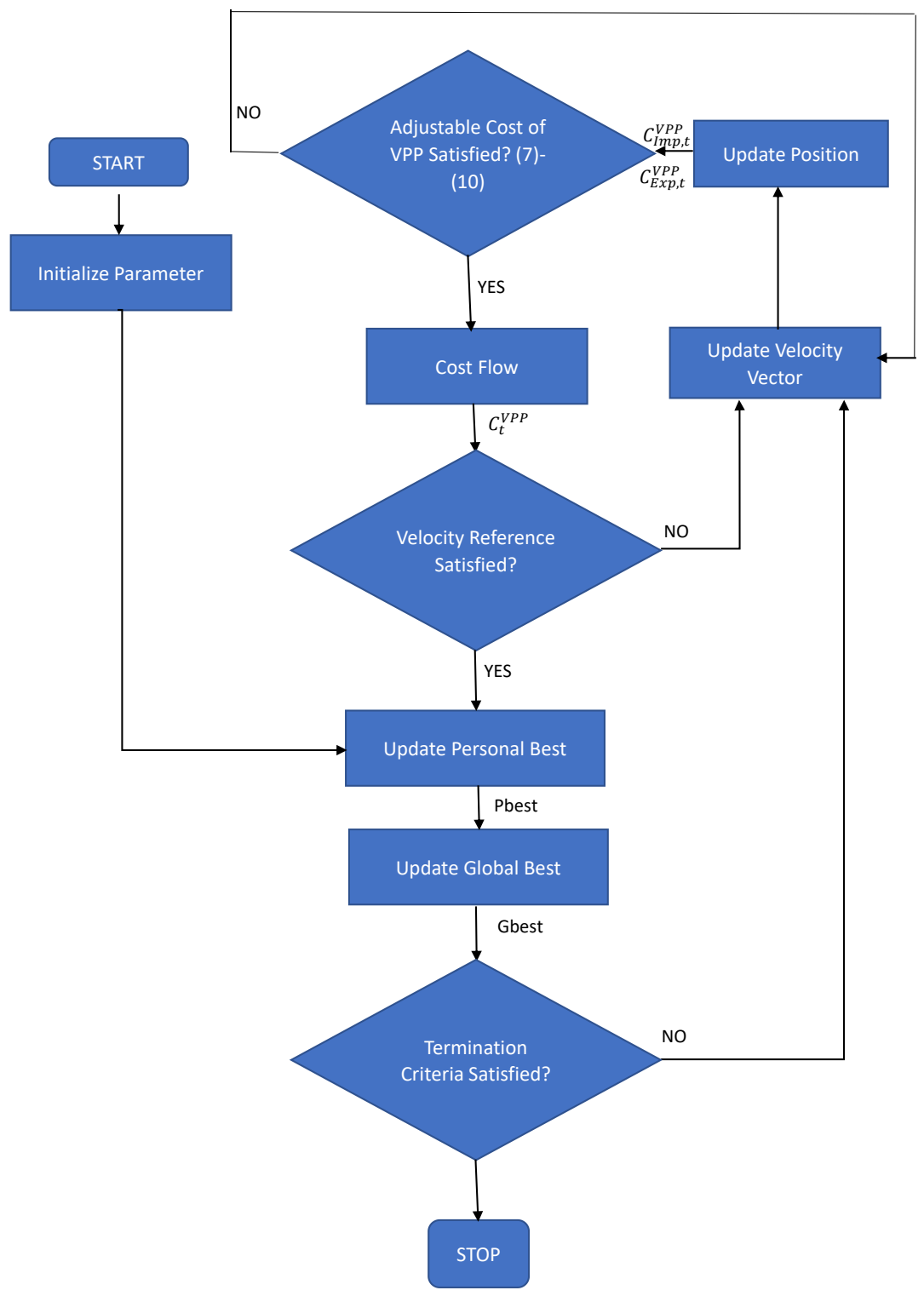

Figure 4. PSO algorithm.

The classic PSO's search area is adjusted, which is prompted by elderly and experienced members of the swarm who already know the best and worst locations to search. By employing previously existing knowledge about the system, the search area may be restricted, allowing the algorithm to converge in less time and locate the solution faster. Numerous experimental experiments are performed to confirm the modified PSO, and it is discovered that it converges quicker than the generic PSO. The size for the population is taken as 25 with learning and the weighting factor is 0.2 and 0.7 respectively. To better understand the research methodology, the flowchart is given below in Figure 5. In the initial step, the technical parameters are defined and generation from the various gridconnected PVs is computed after aggregation. The excess $P V$ generation is used to charge the battery, which further supplies the emergency load during grid outages after shifting or curtailing the low priority demand. On the other hand, in grid-connected operation, the load is dispatched through the grid after utilizing the $P V$ generation. The economical 
parameters such as cost of energy and demand charges are fed with technical parameters in the modified PSO for optimal scheduling to minimize the energy cost. The step-wise workflow of the study is illustrated in Figure 5 below.

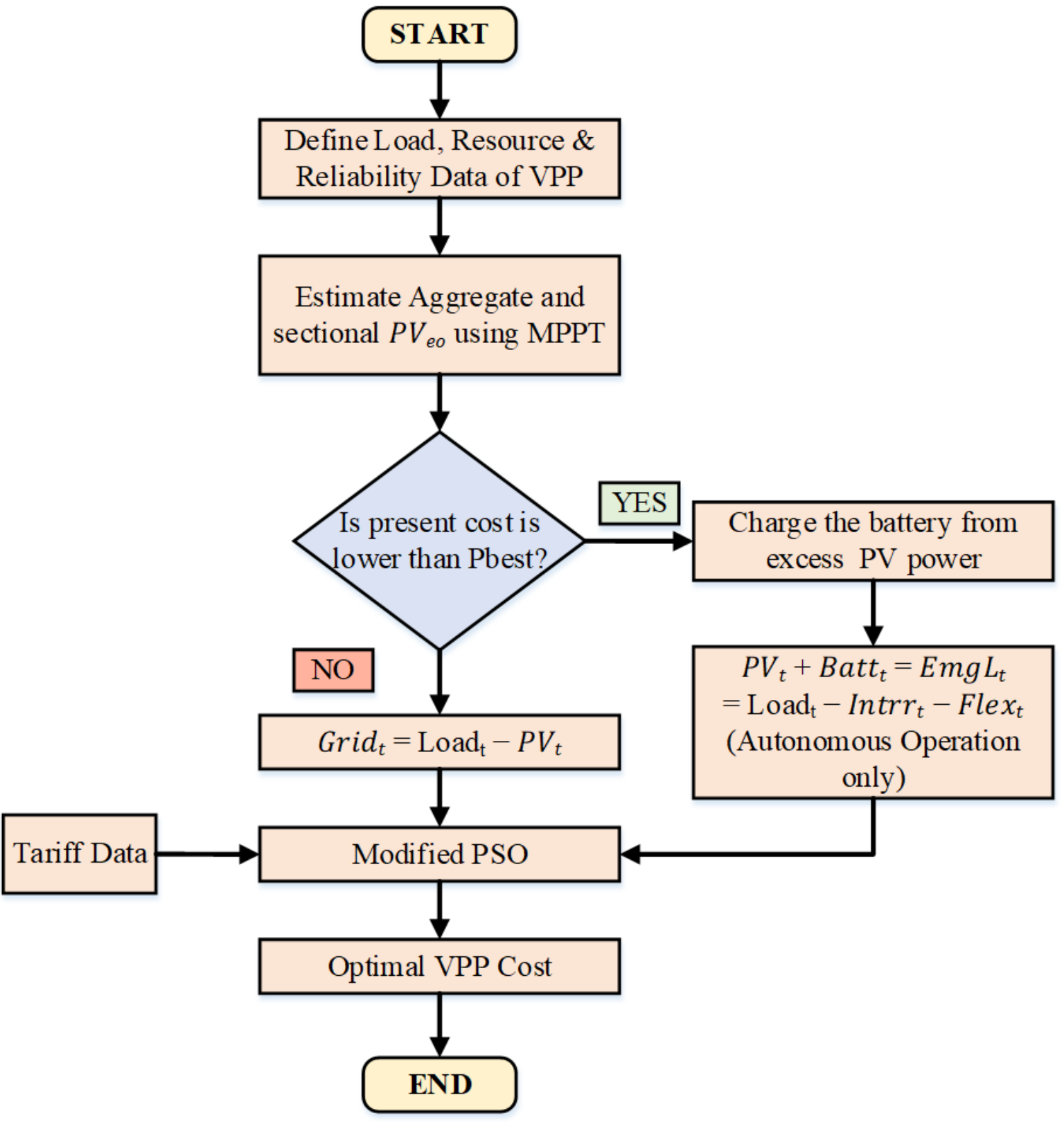

Figure 5. Dispatch Strategy of VPP.

\section{Results and Discussions}

For the techno-economic analysis; the case study is classified into four separate cases and compared with both technical and financial parameters. In the base case, there is no investment is considered and electrical dispatch is only through the utility grid, which is unreliable and expensive. With the inclusion of DER, the part of the demand is dispatched through $P V$ generation, and the remaining $P V$ output is exported to the grid during low demand. The DER integration declines the operational cost by $11.17 \%$ and EENS of the typical section by $68.66 \%$ in comparison to the base case. The implementation of DR further enhances the effectiveness of the VPP by reducing the operational and loss of load cost. Finally, the best scenario is found to be with the addition of the battery storage, in this case, 
the operation cost of the VPP is reduced by $31.57 \%$. The reliability is also increased with the reduction of the EENS and its related loss of load cost by $62.30 \%$. The detailed VPP techno-economic analysis is tabulated in Table 3 below.

Table 3. VPP Techno-economic analysis.

\begin{tabular}{|c|c|c|c|c|}
\hline & Base Case & With DER & With DER \& DR & $\begin{array}{l}\text { With DER, DR \& } \\
\text { Storage }\end{array}$ \\
\hline PV Capacity & - & $1916 \mathrm{~kW}$ & $1916 \mathrm{~kW}$ & $1916 \mathrm{~kW}$ \\
\hline Battery Capacity & - & - & - & $9511 \mathrm{kWh}$ \\
\hline Annual Savings & $\$ 0$ & $\$ 367$ & $\$ 402$ & $\$ 1028$ \\
\hline Optimized operational cost & $\$ 3284$ & $\$ 2917$ & $\$ 2882$ & $\$ 2247$ \\
\hline Total Electricity import & $36,413 \mathrm{kWh}$ & $32,085 \mathrm{kWh}$ & $32,085 \mathrm{kWh}$ & $32,085 \mathrm{kWh}$ \\
\hline Peak Demand & $2945 \mathrm{~kW}$ & $2582 \mathrm{~kW}$ & $2582 \mathrm{~kW}$ & $2250 \mathrm{~kW}$ \\
\hline $\begin{array}{l}\text { EENS during autonomous operation for } \\
\text { during } 10 \text { to } 12 \mathrm{~h} \text { in typical section TU }\end{array}$ & $3491 \mathrm{kWh}$ & $1904 \mathrm{kWh}$ & $1579 \mathrm{kWh}$ & $1316 \mathrm{kWh}$ \\
\hline $\begin{array}{l}P V \text { output for during } 10 \text { to } 12 \mathrm{~h} \text { in } \\
\text { section TU }\end{array}$ & - & $260 \mathrm{kWh}$ & $260 \mathrm{kWh}$ & $260 \mathrm{kWh}$ \\
\hline $\begin{array}{l}\text { DR (load shifting) for during } 10 \text { to } 12 \mathrm{~h} \\
\text { period in section TU }\end{array}$ & - & - & $324 \mathrm{kWh}$ & $324 \mathrm{kWh}$ \\
\hline $\begin{array}{c}\text { Battery output for during } 10 \text { to } 12 \mathrm{~h} \text { in } \\
\text { Section TU }\end{array}$ & - & - & - & $262 \mathrm{kWh}$ \\
\hline
\end{tabular}

\subsection{Grid Connected Mode}

In this mode, the load is dispatched from the combined scheduling of the main grid and VPP. The detailed analysis of various cases are as follows:

\subsubsection{Base Case}

It is the reference case in which there is no investment is done and the load is completely dispatched from the main grid. The feeder peak demand is significantly higher than the average load, which mostly occurs in the afternoon. The electrical dispatch with the base case is illustrated in Figure 6 below:

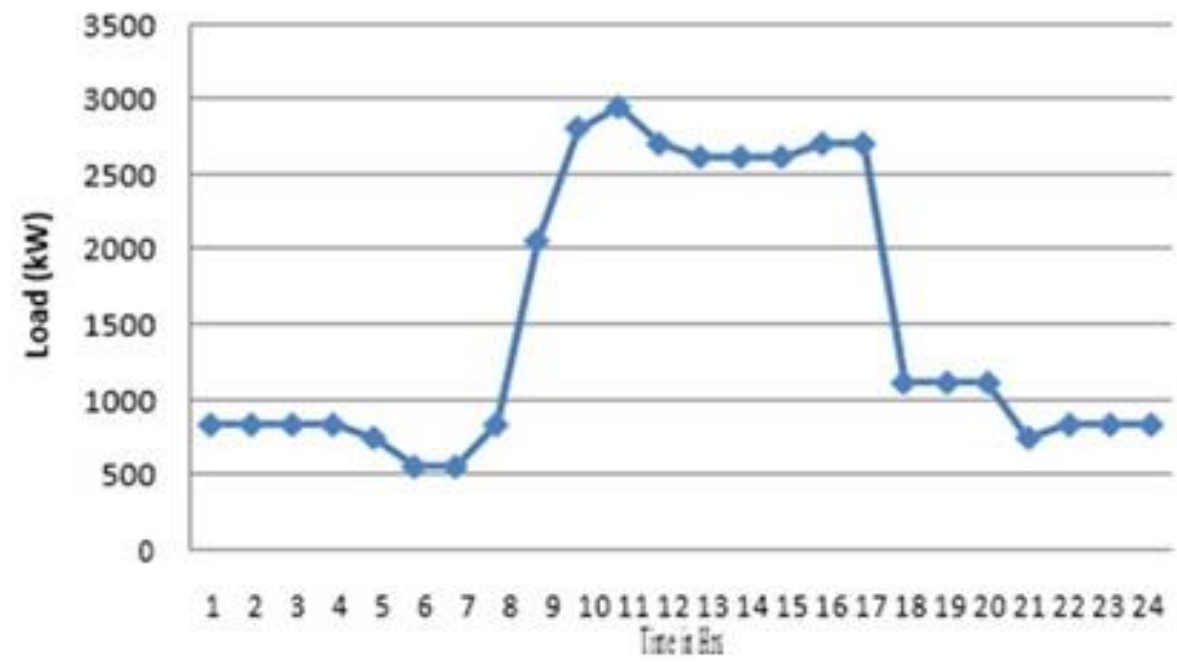

Figure 6. Electrical dispatch with the base case. 


\subsubsection{Case with DER}

The peak load of the industrial feeder is coinciding with the solar generation, which makes the solar $P V$ an effective DER for peak shaving and minimizing energy cost. The electrical dispatch with DER is visualized in Figure 7 below:

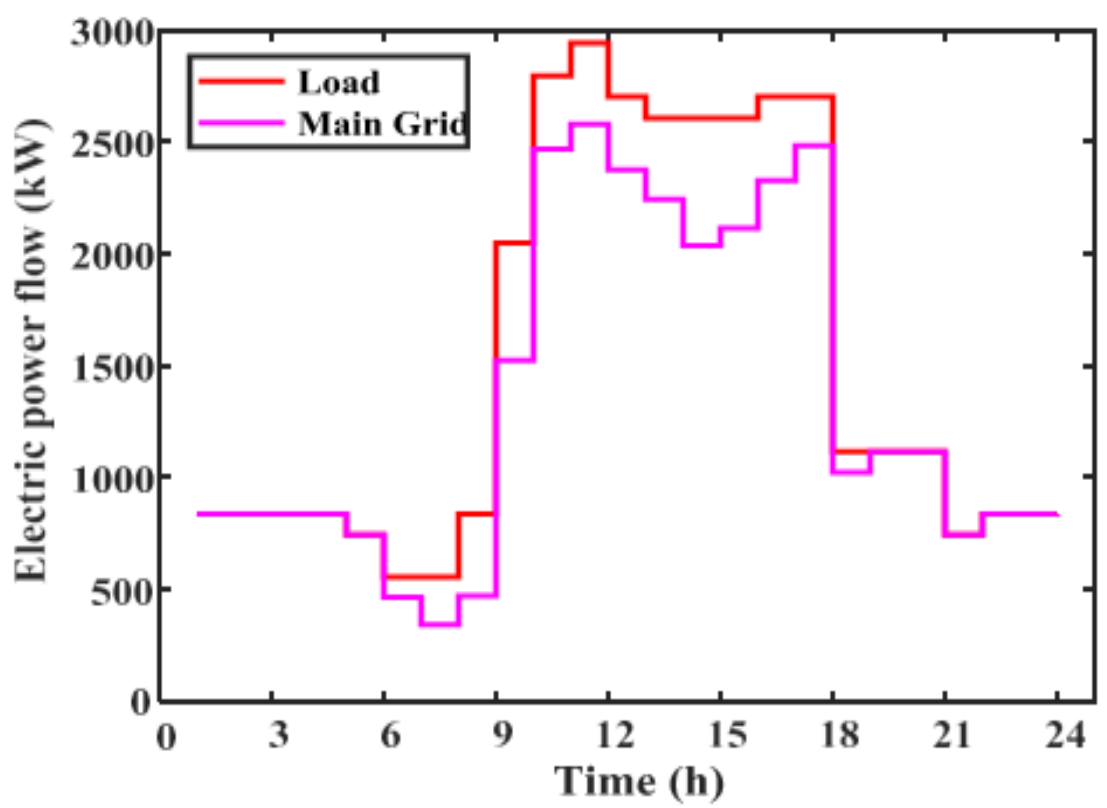

Figure 7. Electrical dispatch with DER.

\subsubsection{Case with DER \& DR}

The addition of DR enhances the utilization of DER having intermittent generation through controlling the load with respect to the generation. The demand is shifted from the peak load period to the off-peak load or peak generation period, which assists in peak shaving and flattening of the demand profile. The electrical dispatch with DER and DR is shown below in Figure 8.

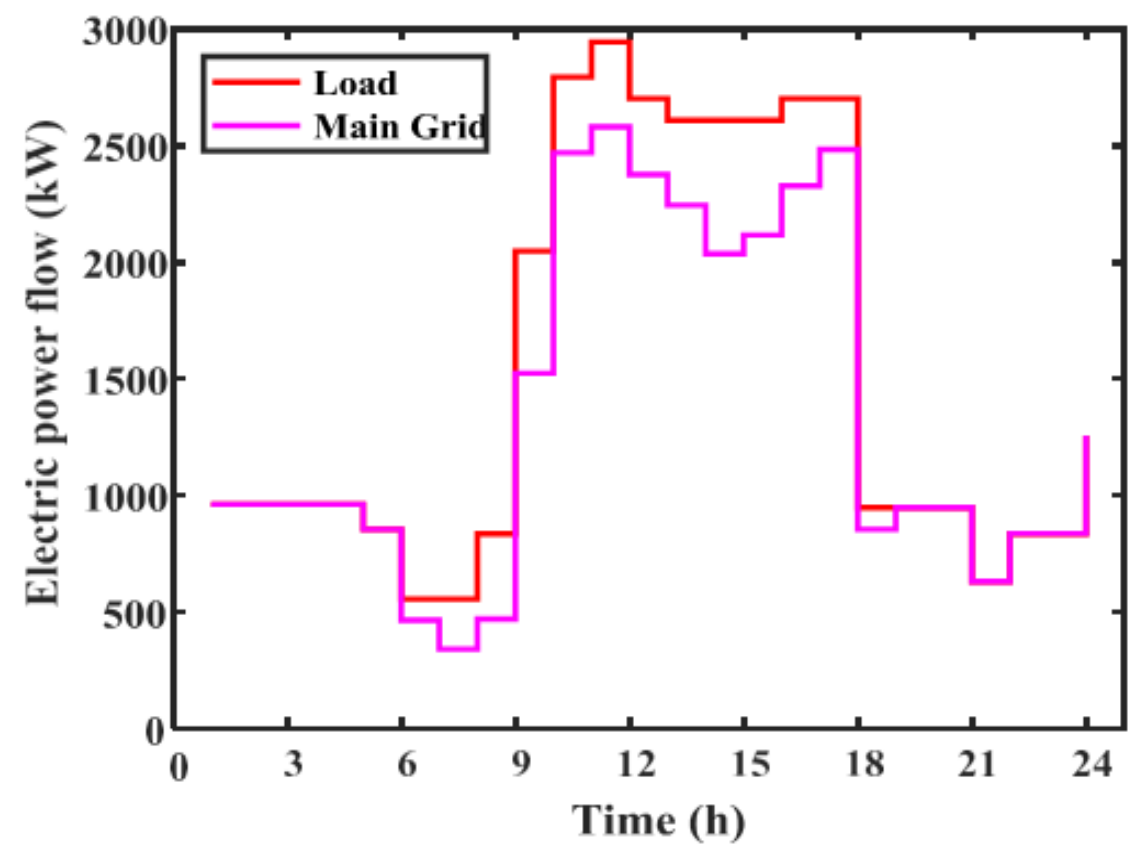

Figure 8. Electrical dispatch with DER \& DR. 


\subsubsection{Case with DER, DR \& Storage}

Energy storage is an effective way to integrate intermittent DERs into the grid by supplying and storing the energy in a suitable duration. The rate of charging and discharging of the battery is also the key factor in designing the storage element of the VPP.

The combined dispatch of DER, DR, and battery significantly reduces energy cost and peak demand than any other scenario. The electrical dispatch of DER, DR, and battery is shown in Figure 9. The storage is a dispatchable resource, and its output is utilized during peak periods or during the night when there is no $P V$ generation.

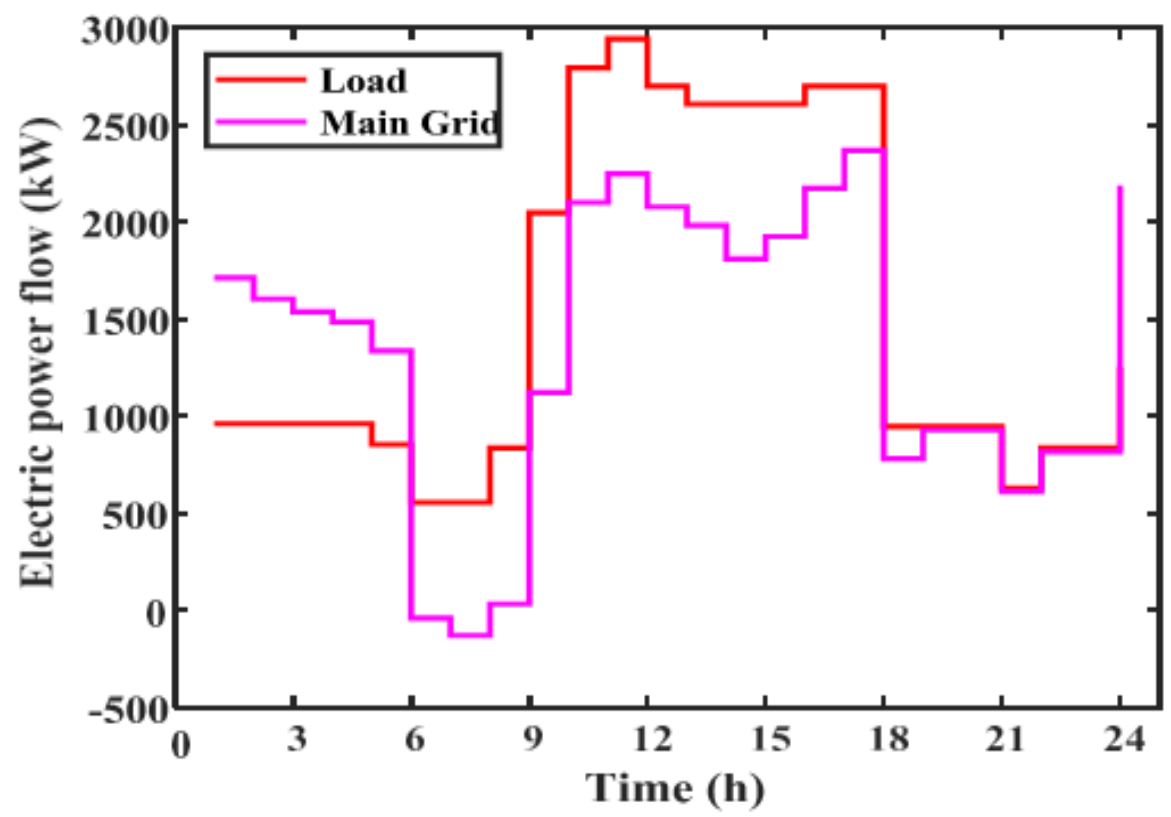

Figure 9. Electrical dispatch with DER, DR \& storage.

\subsection{VPP Autonomous Mode}

During the fault period or schedule shut-down, the whole electricity supply is disrupted due to the grid non-availability, however, the VPP could be a viable way to overcome this issue. The electricity supply is dispatched through the available resources within the VPP framework. The different scenarios of the VPP in autonomous mode are discussed below:

\subsubsection{Case with DER and Storage}

During an outage, an emergency or high priority load is dispatched from the aggregated generation of the grid interconnected DERs. The VPP autonomous operation with DER integration is illustrated in Figure 10 below. 


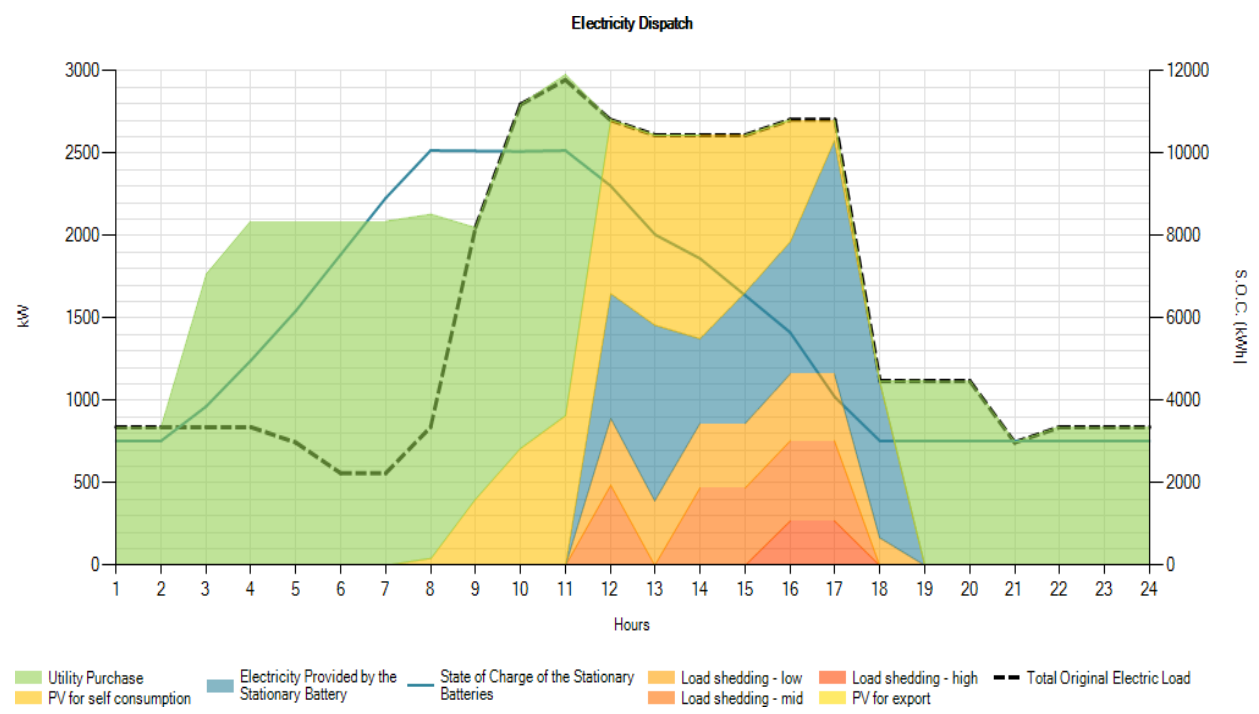

Figure 10. VPP autonomous operation with DER \& storage.

\subsubsection{Case with DER, DR \& Storage}

To reduce the EENS significantly, the combined scheduling of all the resources is done. There is a minimum load is shed during the VPP operation with batteries, which represents the highly cost-effective and reliable system for optimal energy scheduling. The electrical dispatch with DER, DR, and storage is shown below in Figure 11.

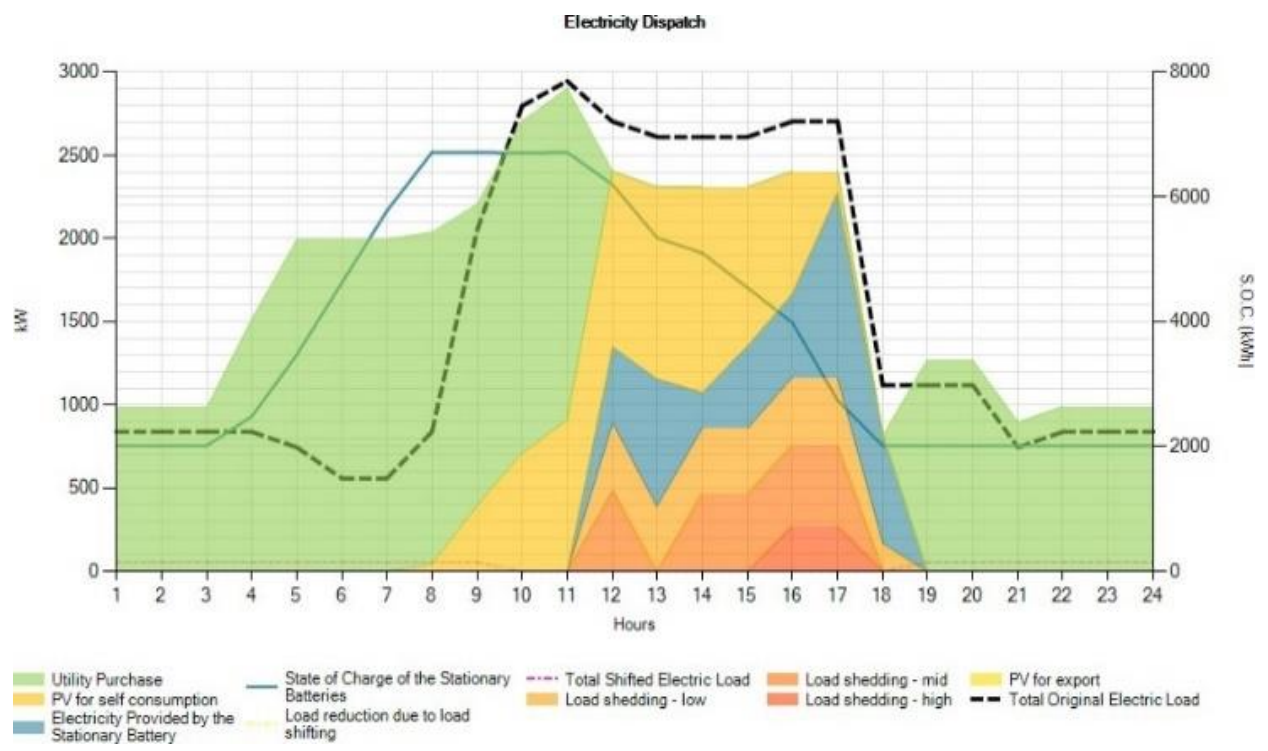

Figure 11. Electrical dispatch with DER, DR, \& storage.

\subsection{Benefits for Consumers}

The industrial unit of induction furnace having a load of $500 \mathrm{~kW}$ has been selected for evaluation for potential benefits of VPP implementation for individual consumers. In this study, a $100 \mathrm{~kW}$ solar rooftop plant as grid integrated DER installed on the consumer premises is evaluated. The load profile of the induction furnace during different days is illustrated in Figure 12 below. The peak or weekday load is much higher than the weekend load as most of the industries are out of operation during weekends. The demand of the industrial furnace is ramping up during the initial heating of the furnace as it is loaded with metal weight, which is from 7 to $9 \mathrm{~h}$. The load remains stable once the furnace attains the required temperature and substantially reduces with emptying the metal load. 


\section{Load Profile}

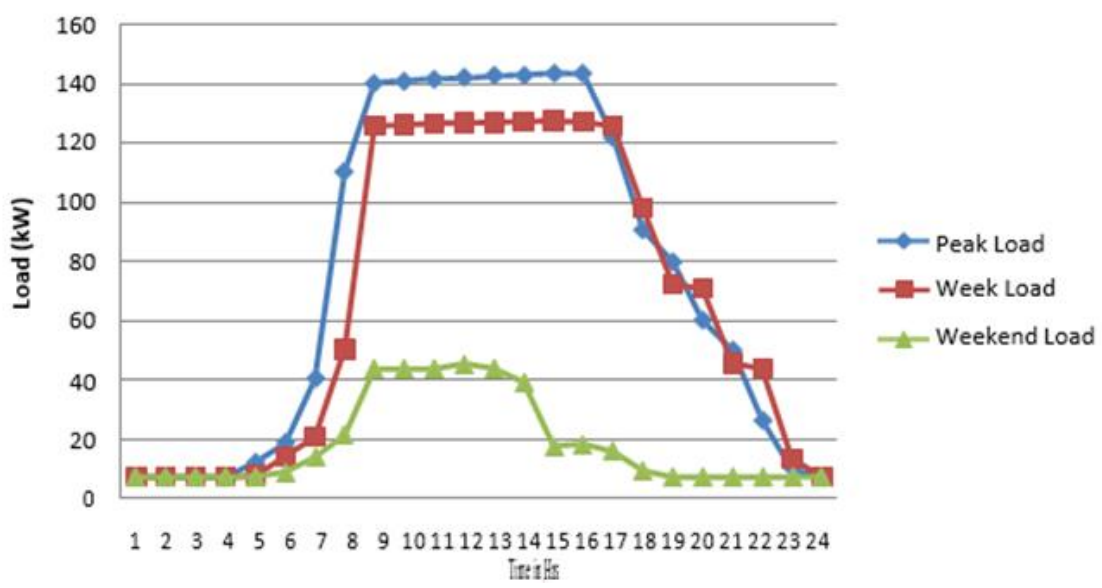

Figure 12. Load profile induction furnace industry.

Influence of VPP on the Energy Charges

The VPP significantly reduces the energy import from the utility and therefore, the energy charges are significantly declined. The resultant hefty saving in the energy bill will motivate the consumers to install the PVs at their premises and further increase the share of $P V$ in the generation sector. The month-wise saving energy charges of the industry are tabulated in Table 4 below.

Table 4. Monthly savings in energy charges.

\begin{tabular}{|c|c|c|c|c|c|c|}
\hline \multicolumn{7}{|c|}{ Energy Charges with TOD Tariff (On = On-Peak; Mid = Mid-Peak; Off = Off-Peak) } \\
\hline & \multicolumn{3}{|c|}{ Charges in \$ without VPP Implementation } & \multicolumn{3}{|c|}{ Charges in \$ with VPP Implementation } \\
\hline Month & on & mid & off & on & mid & Off \\
\hline January & 637.39 & 2906.07 & 137.96 & 464.95 & 1480.49 & 576.54 \\
\hline February & 578.47 & 2673.97 & 121.38 & 345.83 & 1418.59 & 524.55 \\
\hline March & 566.45 & 3050.77 & 142.78 & 312.65 & 1359.35 & 593.26 \\
\hline April & 544.19 & 3167.03 & 147.45 & 288.85 & 1468.1 & 591.64 \\
\hline May & 553.85 & 3215.48 & 151.89 & 263.8 & 1439.22 & 586.75 \\
\hline June & 696.08 & 3050.88 & 187.39 & 180.67 & 2130.61 & 78.23 \\
\hline July & 752.45 & 3265.23 & 197.4 & 183.74 & 2202.05 & 105.45 \\
\hline August & 754.69 & 3289.84 & 196.13 & 192.72 & 2316.59 & 99.35 \\
\hline September & 685.08 & 3038.58 & 186.89 & 166.66 & 2129.64 & 101.47 \\
\hline October & 545.7 & 3176.31 & 150.78 & 271.22 & 1526.44 & 586.59 \\
\hline November & 571.03 & 2760.63 & 125.46 & 336.78 & 1349.21 & 527.29 \\
\hline December & 639.79 & 2952.88 & 134.68 & 459.25 & 1589.36 & 577.26 \\
\hline
\end{tabular}

\section{Comparison with Different Optimization Techniques}

The results of the proposed optimization are compared with other effective optimization techniques for validation. The 90 bus feeder $24 \mathrm{~h}$ load profile and DER profiles are fed to all the optimization techniques for computing the optimal operational energy cost. All three optimization techniques are simulated on the same computer (Intel i3 4 GB RAM). Table 5 gives a detailed comparison between different optimization techniques below $[29,30]$. 
Table 5. Comparison of Different Optimization Techniques.

\begin{tabular}{cc}
\hline Optimization Algorithm & $\begin{array}{c}\text { Optimal Operational } \\
\text { Cost }\end{array}$ \\
\hline System without Optimization & $\$ 3284$ \\
\hline Proprietary Derivative Free & $\$ 2534$ \\
\hline MILP & $\$ 2390$ \\
\hline Proposed PSO & $\$ 2247$ \\
\hline
\end{tabular}

Our proposed PSO provides the minimal cost of electrical dispatch with $11.32 \%$ and 5.98\% less cost in comparison to Proprietary Derivative-Free and MILP respectively. However, the only downside is its execution time, which is significantly higher than the Proprietary Derivative-Free algorithm.

\section{Conclusions}

The study evaluated the feasibility of the VPP multi-objective model for different applications in the utility distribution network. A case study of PSPCL 90 bus Industrial feeder with grid integrated DERs is studied for VPP implementation. A multi-objective model based on the PSO optimization algorithm is proposed for optimal scheduling of utility grid, DER, DR, and battery. The main objective of the proposed model is to minimize the operational energy cost, peak shaving, and reliability enhancement subject to various technical constraints. The model is designed after considering the perspectives of both consumer and utility. The result obtained from the model depicts that VPP deployment is beneficial for both consumer and utility in terms of energy charges and EENS, which are declined by $31.57 \%$ and $62.30 \%$ respectively. Moreover, the maximum demand for industrial consumers is significantly reduced as their peak demand coincides with a peak generation of solar $P V$. The VPP with storage comes to be the most cost-effective scenario for the utility network having DER associated with intermittent generation. The overall results advocate the implementation of the VPP for coordination of aggregated generation and optimal scheduling in the distribution network on which several consumers with DERs are present. Lastly, the obtained results are compared with other available optimization techniques, and it is found that the results obtained from the proposed model are more cost-efficient in comparison to other optimization techniques.

The study could be extended, especially with the use of different DERs and storage devices. On the other hand, the grid protection in terms of voltage fluctuation and system islanding is to be analyzed. The different types of load profiles with the commercial VPP point of view could be the potential area of study.

Author Contributions: Conceptualization, H.S.; methodology, H.S., M.B., S.M. and J.D.; software, H.S. and N.K.S.; validation, H.S., J.D., A.U.R. and M.S.; formal analysis, H.S., M.B., M.S. and H.H.; investigation, M.B., N.K.S., A.U.R. and H.H.; resources, H.S., R.T. and J.D.; data curation, H.S, S.M. and H.H.; writing-original draft preparation, H.S. and J.D.; writing-review and editing, H.S., A.U.R., R.T., M.S. and H.H.; visualization, H.H. and M.S.; supervision, H.S., A.U.R., M.S. and H.H.; All authors have read and agreed to the published version of the manuscript.

Funding: This research received no external funding.

Institutional Review Board Statement: Not applicable.

Informed Consent Statement: Not applicable.

Data Availability Statement: Authors may provide data on due request.

Acknowledgments: The authors wish to thank Punjab State Power Corporation Limited for their assistance and valuable information during the conduction of this research. The authors also thank the Natural Sciences and Engineering Research Council of Canada (NSERC) and the New Brunswick 
Innovation Foundation (NBIF) for the financial support of the global project. These granting agencies did not contribute to the design of the study and collection, analysis, and interpretation of data.

Conflicts of Interest: The authors declare no conflict of interest.

\section{Nomenclature and Abbreviations}

\begin{tabular}{|c|c|}
\hline$\eta$ & Efficiency of a solar panel (14.9\%) \\
\hline$S_{t}$ & Solar irradiation $\left(\mathrm{W} / \mathrm{m}^{2}\right)$ \\
\hline$T$ & Time-step (s) \\
\hline$N$ & Number of solar panels connected either in series or parallel \\
\hline$A$ & Area occupied by solar panels $\left(\mathrm{m}^{2}\right)$ \\
\hline$P V_{e o}$ & Estimated output of solar $P V$ \\
\hline $\operatorname{Load}_{t}$ & Total demand on the feeder $(\mathrm{kW})$ \\
\hline Flex $_{t}$ & Schedulable demand $(\mathrm{kW})$ \\
\hline Intrr $_{t}$ & Non Schedulable demand (kW) \\
\hline$E m g_{t}$ & Emergency demand $(\mathrm{kW})$ \\
\hline$P_{t}^{b a t}$ & Operational price of battery in dispatch $(\$)$ \\
\hline$m_{t}^{b a t}$ & Maintenance coefficient of battery \\
\hline$F_{t}^{b a t}$ & Discharging or recharging of the battery \\
\hline$d_{t}^{b a t}$ & Depreciation coefficient of the battery \\
\hline$C_{t}^{V P P}$ & Total Cost of VPP $(\$)$ \\
\hline$C_{t}^{P V}$ & Total Cost of $P V(\$)$ \\
\hline$C_{t}^{b a t}$ & Total Cost of Batteries (\$) \\
\hline$C_{t}^{G r i d}$ & Total cost of Grid (\$) \\
\hline$C_{t}^{E E N S}$ & Total cost of EENS(\$) \\
\hline$C_{I m p, t}^{P s p c l}$ & Purchasing cost of electricity $(\$ / \mathrm{kWh})$ \\
\hline $\operatorname{MaxS}$ & Maximum rating of solar $P V[\mathrm{~kW}]$ \\
\hline$U_{\text {Load }, t}^{\operatorname{Imp}}$ & Energy imported from the grid (kWh) \\
\hline$C_{E E N S}$ & Cost of not supplying demand $(\$ / \mathrm{kWh})$ \\
\hline EENS & Expected Energy Not Supplied (kWh) \\
\hline Ttod & Energy usage charges $[\$ / \mathrm{kWh}]$ \\
\hline $\mathrm{MaxH}$ & Maximum annual operation hours for technology [hour] \\
\hline NS & Number of units of solar $P V$ installed \\
\hline $\operatorname{Dis} R_{t}^{b a t}$ & Discharging rate of the battery (Amps) \\
\hline$C h r R_{t}^{b a t}$ & Charging rate of the battery (Amps) \\
\hline TotCap bat & Total capacity of the battery (Ah) \\
\hline $\mathrm{Cap}_{t}^{\text {bat }}$ & Initial capacity of the battery (Ah) \\
\hline$C_{I m p, t}^{V P P}$ & Cost of VPP of utility imports $(\$ / \mathrm{kWh})$ \\
\hline$C_{E x p, t}^{V P P}$ & Cost of VPP of utility exports $(\$ / \mathrm{kWh})$ \\
\hline$C_{\text {Exp }, t}^{\text {Pspcl }}$ & Selling cost of electricity $(\$ / \mathrm{kWh})$ \\
\hline$P V$ & Photovoltaic \\
\hline ToD & Time of Day \\
\hline MILP & Mixed Integer Linear Programming \\
\hline ETAP & Electrical Transient Analyzer Program \\
\hline$\lambda$ & Failure rate/Year \\
\hline$D G$ & Distributed Generation \\
\hline PSO & Particle Swarm Optimization \\
\hline$D E R$ & Distributed Energy Resource \\
\hline$D S M$ & Demand Side Management \\
\hline$V P P$ & Virtual Power Plant \\
\hline PSPCL & Punjab State Power Corporation Limited \\
\hline NREL & National Renewable Energy Laboratory \\
\hline HOMER & Hybrid Optimization Model For multiple Energy Resources \\
\hline$S C A D A$ & Supervisory Control and Data Acquisition \\
\hline
\end{tabular}




\section{Appendix A}

\section{MPPT Algorithm A1.}

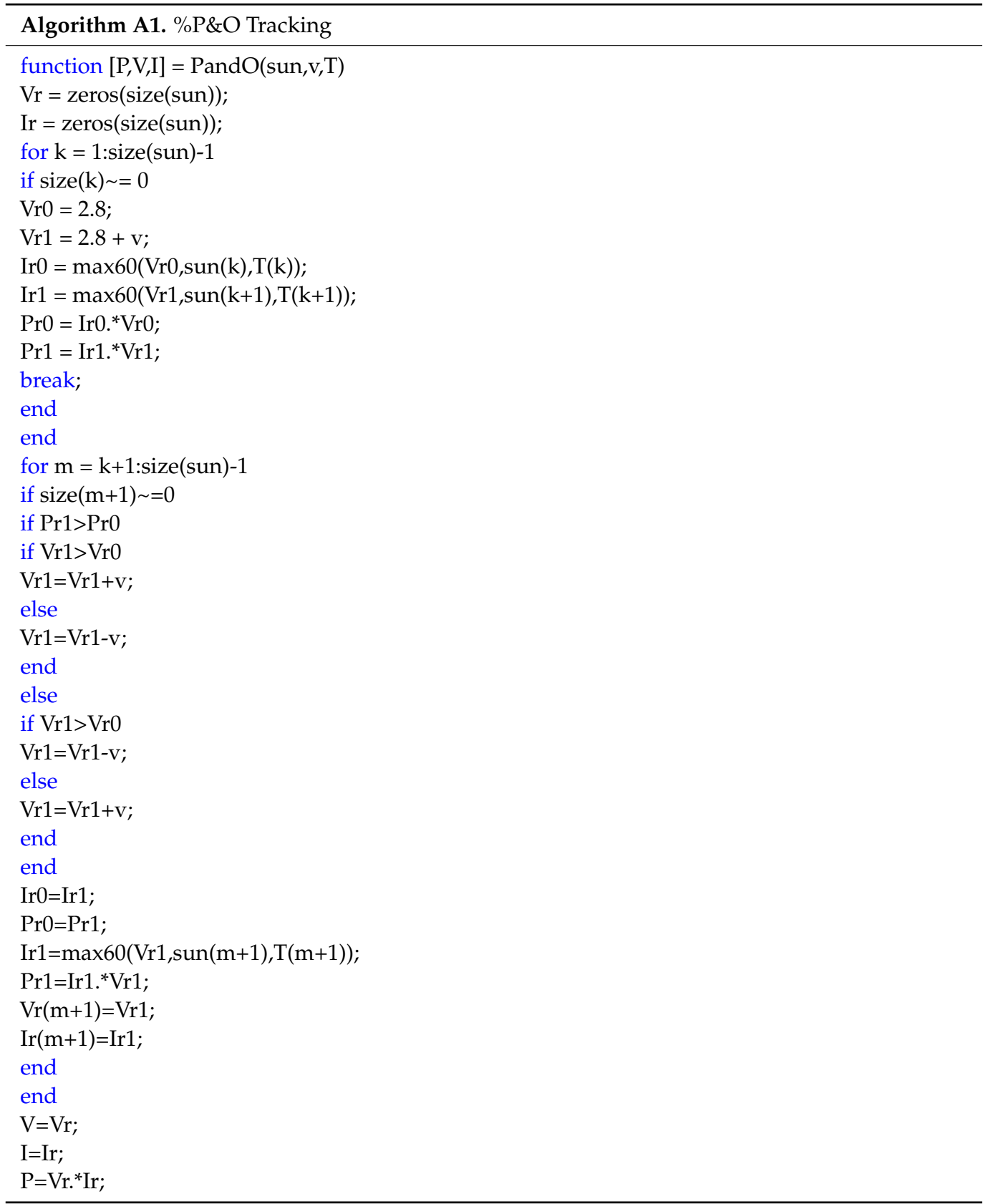




\section{Appendix B}

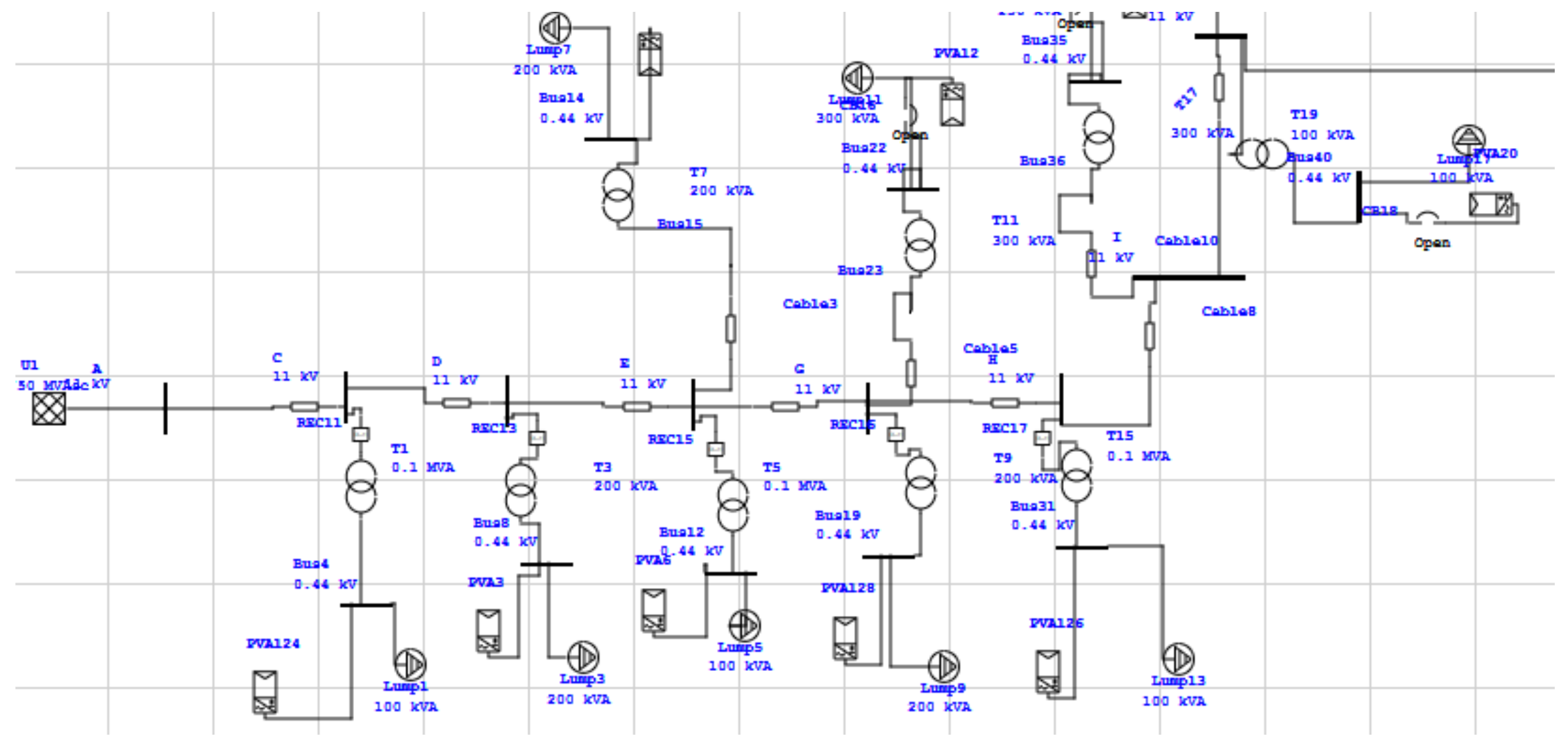

Figure A1. 90 bus 11 kV Industrial feeder in ETAP (Portion of Punjab Power System). 


\section{References}

1. Abdolrasol, M.G.M.; Hannan, M.A.; Hussain, S.M.S.; Ustun, T.S.; Sarker, M.R.; Ker, P.J. Energy Management Scheduling forMicrogrids in the Virtual Power PlantSystem Using Artificial Neural Networks. Energies 2021, 14, 6507. [CrossRef]

2. $\quad$ Oest, F.; Radtke, M.; Blank-Babazadeh, M.; Holly, S.; Lehnhoff, S. Evaluation of Communication Infrastructures for Distributed Optimization of Virtual Power Plant Schedules. Energies 2021, 14, 1226. [CrossRef]

3. Kaczorowska, D.; Rezmer, J.; Jasinski, M.; Sikorski, T.; Suresh, V.; Leonowicz, Z.; Kostyla, P.; Szymanda, J.; Janik, P. A Case Study on Battery Energy Storage System in a Virtual Power Plant: Defining Charging and Discharging Characteristics. Energies 2020, 13, 6670. [CrossRef]

4. Nghitevelekwa, K.; Bansal, R.C. A review of generation dispatch with large-scale photovoltaic systems. Renew. Sustain. Energy Rev. 2017, 81, 615-624. [CrossRef]

5. Müller, T.; Möst, D. Demand Response Potential: Available when Needed? Energy Policy 2017, 115, 181-198. [CrossRef]

6. Gu, C.; Yan, X.; Yan, Z.; Li, F. Dynamic pricing for responsive demand to increase distribution network e fficiency. Appl. Energy 2017, 205, 236-243. [CrossRef]

7. Vallés, M.; Reneses, J.; Cossent, R.; Frías, P. Regulatory and market barriers to the realization of demand response in electricity distribution networks: A Europeanperspective. Electr. Power Syst. Res. 2016, 140, 689-698. [CrossRef]

8. Eid, C.; Codani, P.; Perez, Y.; Reneses, J.; Hakvoort, R. Managing electric flexibility from Distributed Energy Resources: A review of incentives for market design. Renew. Sustain. Energy Rev. 2016, 64, 237-247. [CrossRef]

9. Xie, S.; Wang, X.; Qu, C.; Wang, X.; Guo, J. Impacts of different wind speed simulation methods on conditional reliability indices. Int. Trans. Electr. Energy Syst. 2013, 20, 1-6.

10. Ahmad, S.; Naeem, M.; Ahmad, A. Low complexity approach for energy management in residential buildings. Int. Trans. Electr. Energy Syst. 2019, 29, 1-19. [CrossRef]

11. Ahmad, S.; Ahmad, A.; Naeem, M.; Ejaz, W.; Kim, H.S. A compendium of performance metrics, pricing schemes, optimization objectives, and solution methodologies of demand side management for the smart grid. Energies 2018, 11, 2801. [CrossRef]

12. Cui, H.; Li, F.; Hu, Q.; Bai, L.; Fang, X. Day-ahead coordinated operation of utility- scale electricity and natural gas networks considering demand response based virtual power plants. Appl. Energy 2016, 176, 183-195. [CrossRef]

13. Nosratabadi, S.M.; Hooshmand, R.; Gholipour, E. Stochastic profit-based scheduling of industrial virtual power plant using the best demand response strategy. Appl. Energy 2016, 164, 590-606. [CrossRef]

14. Yin, S.; Ai, Q.; Li, Z.; Zhang, Y.; Lu, T. Electrical Power and Energy Systems Energy management for aggregate prosumers in a virtual power plant: A robust Stackelberg game approach. Electr. Power Energy Syst. 2020, 117, 105605. [CrossRef]

15. Liu, Y.; Li, M.; Lian, H.; Tang, X.; Liu, C.; Jiang, C. Electrical Power and Energy Systems Optimal dispatch of virtual power plant using interval and deterministic combined optimization. Electr. Power Energy Syst. 2018, 102, 235-244. [CrossRef]

16. Zamani, A.G.; Zakariazadeh, A.; Jadid, S.; Kazemi, A. Electrical Power and Energy Systems Stochastic operational scheduling of distributed energy resources in a large scale virtual power plant. Int. J. Electr. Power Energy Syst. 2016, 82, 608-620. [CrossRef]

17. Ju, L.; Tan, Q.; Lu, Y.; Tan, Z.; Zhang, Y.; Tan, Q. Electrical Power and Energy Systems A CVaR-robust-based multi-objective optimization model and three-stage solution algorithm for a virtual power plant considering uncertainties and carbon emission allowances. Electr. Power Energy Syst. 2019, 107, 628-643. [CrossRef]

18. Wang, H.; Riaz, S.; Mancarella, P. Integrated techno-economic modeling, flexibility analysis, and business case assessment of an urban virtual power plant with multi-market co- optimization. Appl. Energy 2019, 259, 114142. [CrossRef]

19. Yusta, J.M.; Naval, N.; Raul, S. A virtual power plant optimal dispatch model with large and small- scale distributed renewable generation. Renew. Energy 2020, 19, 57-69.

20. Hadayeghparast, S.; Farsangi, A.S.; Shayanfar, H. Day-ahead stochastic multi- objective economic/emission operational scheduling of a large scale virtual power plant. Energy 2019, 172, 630-646. [CrossRef]

21. Sakr, W.S.; Abd, H.A.; El-sehiemy, R.A.; Azmy, A.M. Techno-economic assessment of consumers' participation in the demand response program for optimal day-ahead scheduling of virtual power plants. Alex. Eng. J. 2020, 59, 399-415. [CrossRef]

22. Magdy, F.E.Z.; Ibrahim, D.K.; Sabry, W. Energy management of virtual power plants dependent on electro-economical model. Ain Shams Eng. J. 2020, 11, 643-649. [CrossRef]

23. PSPCL Installed Capacity. 2018. Available online: https://www.pspcl.in/about-us/statistics (accessed on 1 September 2021).

24. Rashid, M.M.U.; Alotaibi, M.A.; Chowdhury, A.H.; Rahman, M.; Alam, M.S.; Hossain, M.A.; Abido, M.A. Home Energy Management for Community Microgrids Using Optimal Power Sharing Algorithm. Energies 2021, 14, 1060. [CrossRef]

25. PSPCL Tariff. 2018. Available online: http://docs.pspcl.in/docs/sesalesto20180719161203100.pdf (accessed on 1 September 2021).

26. Kita, E.; Shin, Y.B. Application of Particle Swarm Optimization to Packing Problem. WIT Transactions on the Built Environment, Vol 125, Computer Aided Optimum Design in Engineering XII. Available online: https://www.witpress.com/elibrary/wittransactions-on-the-built-environment/125/23515) (accessed on 22 December 2021).

27. Yousif, M.; Ai, Q.; Gao, Y.; Wattoo, W.A.; Jiang, Z. Application of Particle Swarm Optimization to a Scheduling Strategy for Microgrids Coupled with Natural Gas. Energies 2018, 11, 3499. [CrossRef]

28. Yousif, M.; Ai, Q.; Member, I.; Gao, Y.; Wattoo, W.A.; Jiang, Z. An Optimal Dispatch Strategy for Distributed Microgrids using PSO. CSEE J. Power Energy Syst. 2019, 6, 723-724. [CrossRef] 
29. Sharma, H.; Mishra, S. Techno-economic analysis of solar grid-based virtual power plant in Indian power sector: A case study. Int. Trans. Electr. Energy Syst. 2019, 30, e12177. [CrossRef]

30. Sharma, H.; Mishra, S. Optimization of Solar Grid-Based Virtual Power Plant Using Distributed Energy Resources Customer Adoption Model: A Case Study of Indian Power Sector. Arabian J. Sci. Eng. 2021, 1-21. [CrossRef] 